\title{
БИОМЕХАНИЧЕСКИЕ ОСНОВЫ ТЕХНИКИ УДАРНЫХ ДВИЖЕНИЙ РУКАМИ В РУКОПАШНОМ БОЕ
}

\section{BIOMECHANICAL BASICS OF THE TECHNIQUE OF STRIKING HAND MOVEMENTS IN HAND-TO-HAND COMBAT}

\section{N. Grudnitskaya R. Volikov \\ O. Tishchenko}

Summary: The article reveals the biomechanical foundations of striking hand movements in martial arts (hand-to-hand combat, boxing, karate, kickboxing), studies are carried out, a comparative analysis is made, and differences in power, speed-power and biomechanical indicators are revealed when striking with the hands of representatives of various qualification groups (1st category, candidate for master of sports, master of sports). Also, the most favorable conditions for the manifestation of the highest indicators of shock movements, and recommendations for the development of experimental methods for improving general and special strength training in hand-to-hand combat are identified.

Keywords: hand-to-hand combat, shock types of martial arts; biomechanical basics; various qualification groups; shock movement; impact force; speed and power indicators; kinematic structure; vertical axis of rotation.
Грудницкая Наталья Николаевна

К.п.н., дочент, Северо-Кавказский федеральный университет, г. Ставрополь.

Воликов Руслан Александрович

Тренер-преподаватель, Ставропольский колледж сервисных технологий и коммерции, г. Ставрополь. volikov-2014@mail.ru

тищенко Олег Николаевич

Тренер-преподаватель, МБУ СШ «Единоборств» г. Ставрополь

Аннотация: В статье раскрываются биомеханические основы ударных движений руками в спортивных единоборствах (рукопашный бой, бокс, каратэ, кикбоксинг), осуществлены исследования, произведён сравнительный анализ, и выявлены различия силовых, скоростно-силовых и биомеханических показателей, при нанесении ударов руками представителями разнообразных квалификационных групп (1-й разряд, кандидат в мастера спорта, мастер спорта). Также выявлены наиболее благоприятные условия для проявления наиболее высоких показателей ударных движений, и рекомендации по разработки экспериментальной методики по совершенствованию общей и специальной силовой подготовленности в рукопашном бое.

Ключевые слова: рукопашный бой, ударные виды спортивных единоборств; биомеханические основы; разнообразные квалификационные группы; ударное движение; сила удара; скоростно-силовые показатели; кинематическая структура; вертикальная ось вращения.

Проблема раскрытия биомеханических особенностей ударных движений в рукопашном бое всегда была актуальна, и на сегодняшний день остается до конца нерешенной.

Объектом нашего исследования стал учебно-тренировочный процесс единоборцев разного уровня квалификации.

Предметом исследования для нас стал анализ скоростно-силовых и биомеханических показателей при ударах единоборцами разного уровня квалификации.

Целью исследования является выявление уровня специальной силовой подготовки единоборцев разного уровня квалификации (1-й разряд, кандидат в мастера спорта, мастер спорта) на основе анализа биомеханических характеристик при нанесении ударов руками.

\section{Захачи исслемования}

1. Выявить показатели скоростно-силовых и биомеханических характеристик техники ударов рука- 
ми у единоборцев разнообразных квалификаций.

2. Провести сравнительный анализ скоростно-силовых и биомеханических характеристик техники ударов руками у единоборцев разнообразных квалификаций и выявить наиболее благоприятные биомеханические условия для проявления максимальных показателей ударных движений.

Гипотеза исследования состояла в том, что уровень специальной силовой подготовки единоборцев разнообразного уровня квалификаций (1-й разряд, кандидат в мастера спорта, мастер спорта) повышается на основе улучшения биомеханических и скоростно-силовых показателей при ударах руками.

Новизна состоит в том, что получены новые экспериментальные данные, характеризующие скоростносиловые и биомеханические показатели, позволяющие выявить наиболее благоприятные биомеханические условия для проявления максимальных показателей ударных движений в рукопашном бое.

Для решения поставленных в работе задач использовались следующие методы научного исследования:

- ретроспективный анализ литературных источников;

- видеоциклография;

- регистрация скоростно-силовых характеристик ударных движений единоборцев;

- методы математико-статистической обработки материалов исследования.

Для этого были зафиксированные скоростно-силовые и биомеханические показатели у 39 спортсменов, которые были разделены на три группы по такому признаку, как: квалификация (МС - 13 спортсменов; КМС - 15 спортсменов; 1 разряд - 11 спортсменов).

Изучение источников научной, учебно-методической литературы по теме исследования, а также информации в сети Интернет показало, что увеличение силы ударов обеспечиваются следующими основными фазами ударного движения: отталкивающим разгибанием ноги, вращательно-поступательным вращением туловища, ударным движением ударной части перчатки к цели [3].

Указанная последовательность работы звеньев тела в ударном движении подтверждается исследованиями биодинамических особенностей движений в кикбоксинге и боксе рядом исследователей $[4,6]$. Была установлена строгая последовательность в ударных движениях в боксе мышц ног, туловища и рук, а также рациональное распределение сил, передаваемых от дистального звена к проксимальному корпусу. Нарушения в установленной координации движений конечностей и туловища приводят к значительному снижению силовых характеристик ударов, независимо от весовой категории, тактического амплуа спортсмена.

В своей работе специалисты [2, 3] установили, что при выполнении акцентированных ударов с установкой «на максимальную силу» мастера боевых искусств вращают туловище вокруг вертикальной оси с одновременным толчком от опоры правой или левой ногами. Чуть позже руки разгибаются в локтевых суставах, а кулаки с возрастающей силой и скоростью движутся к цели. При этом туловище продолжает поворачиваться и отталкивать ноги от опоры, плечи выдвигаются вперед. Кроме того, общий центр тяжести тела, предварительно спроецированный на середину опорной зоны, смещается к ее передней границе и проецируется на центр левой или правой стопы, стоящей впереди. В конце ударных движений бойцы опираются на левую или правую ноги, слегка повернуты половиной тела к противнику, плечи вытянуты вперед и находятся на уровне передней границы опоры, руки развернуты в локтевых суставах.

В том случае, если расстояние до цели больше длины вытянутой руки, а прямые удары должны выполняться без предварительного шага, бойцы слегка наклоняются вперед - вперед, чтобы еще больше выдвинуть вперед свои плечи. Эти дополнительные движения позволяют достичь намеченной цели. При выполнении ударов с установкой «на максимальную скорость» начальный этап ударных движений сохраняется полностью: боец поворачивает туловище вокруг вертикальной оси с одновременным отталкиванием от опор своих ног, затем выполняет ударные движения руками в сторону оппонента. Но с самого начала движения рук повороты туловища почти прекращаются, а удары происходят за счет движения только одной руки. При этом удары быстрее по скорости движения кулаков, но менее эффективны по силе.

А.Ю. Вагин [1] в своих исследованиях обнаружил, что наиболее значимыми биомеханическими характеристиками при ударах каратэ являются: время отталкивания от опоры и время всего удара, максимальная скорость общего центра тяжести тела при отталкивании от опоры, скорость отталкивания от опоры, звено удара и величина ударной массы. При нанесении прямого удара рукой по площадке ударное звено ускоряется за счет механизмов хлыста и обратного движения верхнего плечевого пояса, а также непроникающей руки относительно продольной оси тела.

Учитывая кинематическую структуру тела бойца, его ось вращения и точку опоры при нанесении удара, можно отметить, что работа нижней части тела бойца при нанесении ударов осуществляется по трехзвенной кинематической цепи: стопа - нога - бедро. Он передает поступательное движение телу, способствуя ускорению 
вращения таза. При опоре на левую ногу вращение происходит вокруг вертикальной оси, проходящей через левую стопу, левый тазобедренный сустав. При отдыхе на правой ноге соответственно вращение происходит вокруг оси, проходящей через правую стопу, правый тазобедренный сустав. Диагональная ось вращения при опоре на левую стопу проходит через левую стопу, правый тазобедренный сустав; при опоре на правую стопу через правую стопу, левый тазобедренный сустав.

Установленный механизм увеличения скорости звеньев тела при ударе в литературе сравнивают с «волной» или «движением хлыста». Ударные движения квалифицированных единоборцев выполняются в виде последовательной волны напряжения мышц, направленной снизу - вверх. Одновременная активация всех мышц в начальной фазе движения наблюдается только у начинающих, неквалифицированных спортсменов в ударных видах единоборств.

Проведя сравнительный анализ биомеханических и силовых показателей при нанесении ударов руками единоборцами разнообразных квалификаций, мы выявили наиболее благоприятные условия для проявления максимальных показателей ударных движений.

Результаты исследования позволили выявить различия показателей ударных движений спортсменов разнообразных квалификаций (рис. 1, 2).

По всем силовым, скоростно-силовым МС достоверно опережают 1-разрядников и КМС.

Установлено, что максимальная сила максимальная сила прямых ударов левой и правой руками, у МС 366,9 кгс, 505,1 кгс соответственно, что достоверно выше $(<0,05)$, чем у КМС и 1- разрядника, 331,5 кгс, 472,2 кгс, и 316,6 кгс, 363,5 кгс, соответственно. Такая закономерность наблюдается и при максимальной силе боковых ударов левой и правой руками, у МС 529,6 кгс и 548,5 кгс соответственно, что достоверно выше $(<0,05)$ чем у КМС и 1- разрядника, 439,2 кгс, 496,2 кгс, и 396,3 кгс, 436,6 кгс, соответственно (табл. 1).

Это подтверждается нашим исследованием, где при нанесении бокового удара правой рукой в голову у МС, ось вращения проходит через левую ногу и левое плечо, о чем свидетельствует расстояние от вертикальной оси вращения до цели, которое соответственно у МС равно 84,1 см. В то же время, у спортсменов 1 разряда она составляет - 76,2 см, у КMC - 81,3 см.

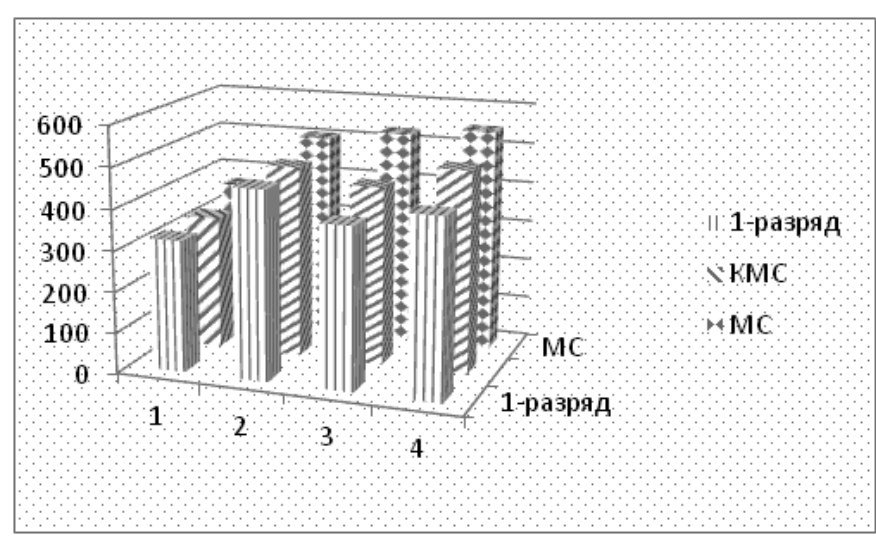

Рис. 1. Скоростно-силовые показатели ударных движений руками единоборцев разнообразных квалификаций: 1- максимальная сила прямого удара левой рукой

(кгс); 2 - максимальная сила прямого удара правой

рукой (кгс); 3 - максимальная сила бокового удара левой рукой (кгс); 4- максимальная сила бокового удара правой рукой (кгс).

Аналогичная картина наблюдается и при анализе показателей дистанции, с которой наносится удар по оппоненту, у МС - 69,5 см, при сравнении с КМС - 65,3 см и 1 - разрядниками - 62,2 см. По-видимому, у боксеров МС это связано с более тонким чувством дистанции для нанесения быстрых и сильных ударов, которые присущи вышеперечисленным спортсменам (рис.2).

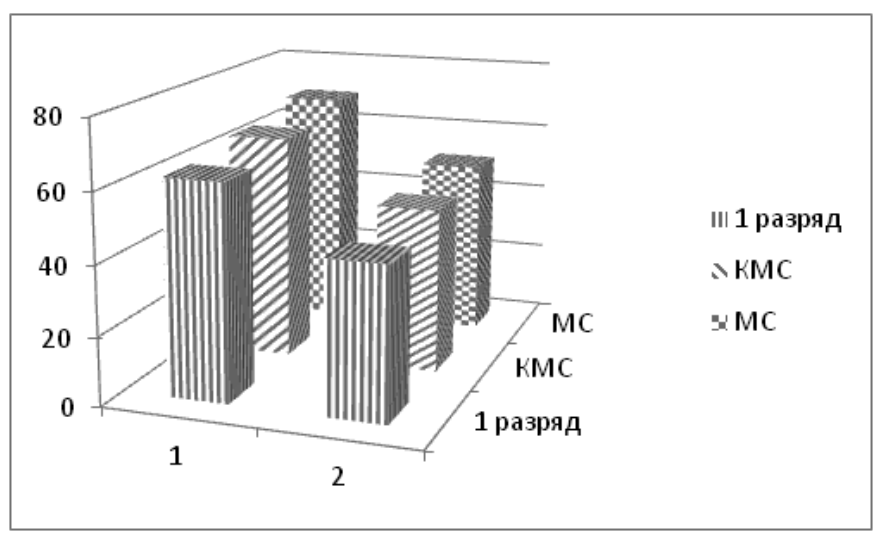

Рис. 2. - Биомеханические показатели ударных движений руками единоборцев разнообразных квалификаций: 1 -дистанция при ударах руками; 2- расстояние от кулака до вертикальной оси вращения при боковом ударе рукой.

Этот факт подтверждает мнение некоторых специалистов [6] о том, что наиболее сильные удары левой и правой руками производятся при максимальном удалении вертикальной оси вращения от цели. С учетом полученных результатов можно рекомендовать в учебнотренировочном процессе спортсменов ударных видов единоборств высокой квалификации, при совершенствовании техники ударов особое внимание уделять 
Таблица 1.

Достоверность по t критерию Стьюдента скоростно-силовых показателей ударных движений руками единоборцами разнообразных квалификаций

\begin{tabular}{|l|c|c|c|c|c|c|}
\hline \multicolumn{1}{|c|}{ Показатели } & \multicolumn{2}{c|}{ 1-разряд (n-13) } & \multicolumn{2}{c|}{ KMC(n-15) } & \multicolumn{2}{c|}{ MC(n-11) } \\
\hline Максимальная сила прямого удара левой рукой (кгс) & 3,15 & $<0,01$ & 2,51 & $<0,05$ & 1,49 & $>0,05$ \\
\hline Максимальная сила прямого удара правой рукой (кгс) & 2,92 & $<0,01$ & 2,21 & $<0,05$ & 1,69 & $>0,05$ \\
\hline Максимальная сила бокового удара левой рукой (кгс) & 4,16 & $<0,01$ & 2,29 & $<0,05$ & 2,17 & $>0,05$ \\
\hline Максимальная сила бокового удара правой рукой (кгс) & 3,95 & $<0,01$ & 2,27 & $<0,05$ & 1,85 & $<0.05$ \\
\hline
\end{tabular}

увеличению дистанции ударной части перчатки от вертикальной оси вращения, так как от этого зависит сила и эффективность удара.

Таким образом, увеличение максимальной силы одиночных ударов руками достигается за счет индивидуального совершенствования техники выполнения ударных движений, а именно, когда вертикальная ось вращения в момент нанесения удара удалена от цели на максимально возможное расстояние. расстояние. Так, при выполнении одиночных ударов бойцами рекомендуется перемещать вертикальную ось вращения как можно дальше от боевой части перчатки, т. е., если удар наносится правой рукой, то ось вращение должно проходить через левое плечо и левую опорную ногу, а если удар наносится левой рукой, то ось вращения должна проходить через правое плечо и правую опорную ногу.

Представленные данные свидетельствуют о том, что в процессе сопряжённого совершенствования специальных силовых способностей и технико-тактического мастерства рукопашников, необходимо особое внимание уделять использованию упражнений, способствующих соблюдению указанных выше биомеханических условий, обеспечивающих максимальную силу ударных движений.

Также следует отметить, что причиной возможного отклонения в технике ударных движений, наряду с ошибками в тренировках, может быть недостаточный уровень общей и специальной физической подготовленности единоборца. Отставание в развитии отдельных групп мышц может привести к несовершенству двигательной структуры, к невозможности полного использования силового потенциала при интегральном ударном движении.

\section{Выводы}

1. По всем силовым, скоростно-силовым MC достоверно опережают 1-разрядников и КМС, максимальная сила максимальная сила прямых ударов левой и правой руками, у МС 366,9 кгс, 505,1 кгс соответственно, что достоверно выше $(<0,05)$, чем у КМС и 1- разрядника, 331,5 кгс, 472,2 кгс, и 316,6 кгс, 363,5 кгс, соответственно. Такая закономерность наблюдается и при максимальной силе боковых ударов левой и правой руками, у МС 529,6 кгс и 548,5 кгс соответственно, что достоверно выше $(<0,05)$ чем у КМС и 1- разрядника, 439,2 кгс, 496,2 кгс, и 396,3 кгс, 436,6 кгс, соответственно.

2. Наиболее сильные удары руками (особенно правой) имеют место в таких биомеханических условиях выполнения ударного движения, когда вертикальная ось вращения туловища бойца максимально удалена от цели. Наиболее ярко это проявляется при сравнении силы ударов МС и перворазрядников.

\section{Рекоменьации}

В заключение отметим, что при разработке экспериментальной методики по совершенствованию общей и специальной силовой подготовленности в ударных видах спортивных единоборств нужно руководствоваться следующими рекомендациями:

- учетом индивидуальных антропометрических показателей и связанных с ними биомеханических условий работы мышц в процессе выполнения ударных движений;

- учетом индивидуальных морфофункциональных особенностей спортсменов при выполнении ими спортивных движений;

- учетом биомеханических особенностей выполнения ударных движений единоборцев разнообразных квалификаций;

- выполнением специальных упражнений и соревновательных скоростно-силовых действий с использованием внешних отягощений;

- использованием принципа сопряжённого совершенствования специализированных силовых способностей и технико-тактического мастерства единоборцев;

- персонификацией средств силовой подготовки на основе учёта индивидуальных антропометрических показателей спортсменов, уровня спортивной квалификации и предрасположенности к тому или иному стилю ведения поединка. 


\section{ЛИТЕРАТУРА}

1. Вагин А.Ю. Биомеханические критерии рациональности и эффективность техники ударных действий в карате: дисс... канд. пед. наук./ Вагин Андрей Юрьевич. М, 2009. 128 с.

2. Иванов А.Л. Кикбоксинг: учебное пособие. 4-е издание, дополненное и переработанное. К., Издатель Корбуш, 2007. 320 с.

3. Поляков В.Г. Методика обучения основным ударам в боксе на базе применения специальных тренажерных устройств: дисс... канд. пед. наук. / Поляков Владимир Гордеевич. М, 1987. 146 с.

4. Топышев 0.П., Джероян Г.О. Биомеханический анализ структуры прямого удара // Бокс. Ежегодник. М.: ФиС, 1978. С.12-14.

5. Филимонов В.И. Педагогическая система физической подготовки боксеров: автореф. дисс. . .док. пед. наук. / Филимонов Василий Иванович. М, 2003. 469 c.

6. Хагай В.С. Рукопашный бой как средство формирования психо - эмоциональной устойчивости военнослужащих: дис. .. канд. пед. наук: 13.00 .04 / Хагай Валерий Сергеевич. - Майкоп, 2008. - 151 с.

7. Хусяйнов 3.М. Формирование ударных движений с учетом скоростно-силовых особенностей боксеров-юношей: автореф. дисс... канд. пед. наук. / Хусяйнов Зофер Мустафович. М, 1983. 32 с.

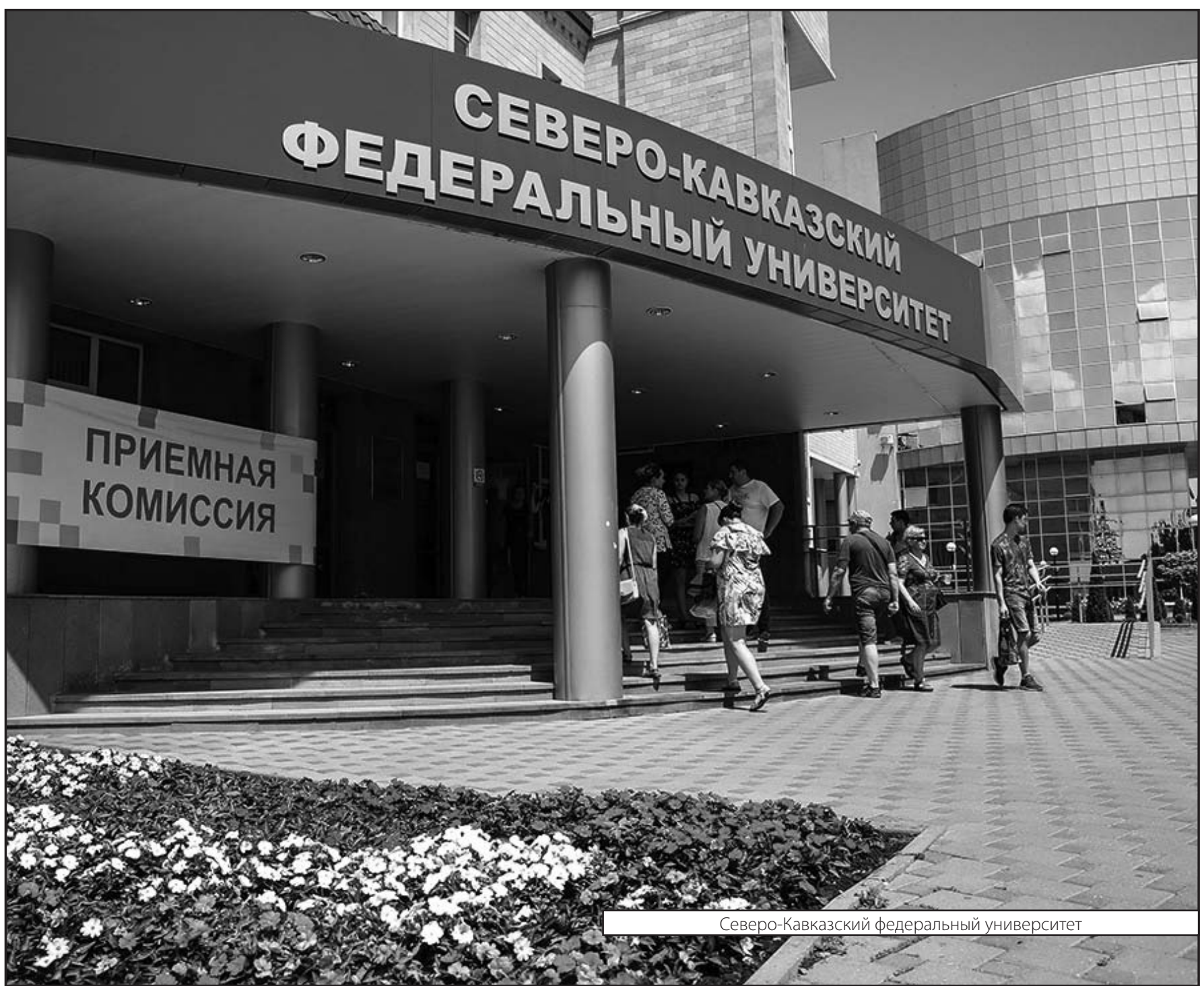

